\section{ENVIRONMENTAL PSYCHOLOGY}

\section{Moral messages}

J. Exp. Psychol. 65, 7-19 (2016)

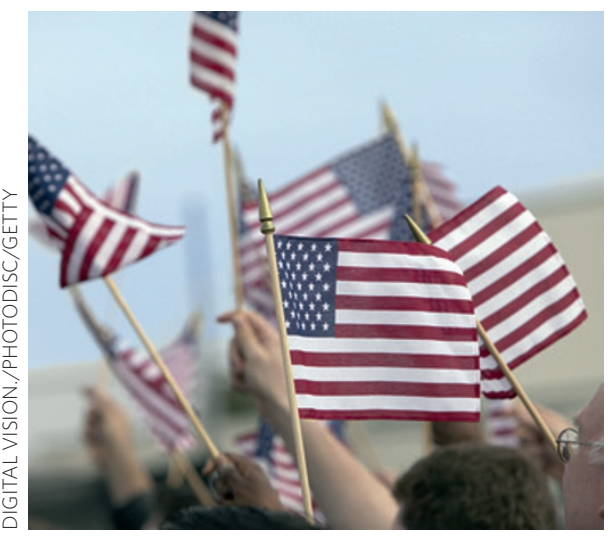

Conservatives in the US are notoriously tricky to engage on issues such as climate change. This could be because the moral basis of environmentalism is seen as inherently liberal, or counter to their group identity.

Christopher Wolsko and colleagues from Oregon State University, USA, analysed the impact of manipulating messages appealing to the moral basis of climate-friendly actions. Across three experiments with different sets of participants, they found that making messages appeal to traditional conservative values affected participants' intentions and actions.

In particular, they found that if they suggested protecting the environment was a matter of obeying authority, defending nature and demonstrating patriotism, it shifted Conservatives' attitudes about climate change and willingness to act in an environmentally friendly way. This effect was particularly strong when participants considered the messages to be coming from members of their own Conservative in-group.

Tailoring messages to a single group can be problematic, however, the authors warn. Ultimately, a shared moral basis will be necessary to stimulate a substantial shift of environmental views and actions across the populace.

\section{ECOLOGY}

\section{Animal movement}

Glob. Change Biol. http://doi.org/bc6r (2016)

A key difficulty in predicting ecological responses to climate change is accounting for food web dynamics, the stability of which depends to a large extent on predator-prey interactions. These are in turn heavily influenced by temperature effects on animal movement.

Jean Gibert, from the University of Nebraska-Lincoln, and co-workers use biomechanical models in combination with observational data to investigate the processes through which temperature affects ectothermic animal movement. They then go on to study the implications of these responses for predator-prey dynamics.

Results suggest that animal movement displays multiple regimes of temperature dependence (rather than simple linear relationships) and that transitioning between these regimes has important consequences for population dynamics and stability. However, the specific consequences were found to depend on the factors that control predator-prey interactions. So, for example, opposing effects were found on population stability in systems with high versus low

\section{CARBON BUDGET}

\section{Asian contribution}

prey-carrying capacity. The authors suggest that this dependence may explain why experimental work on the temperature dependence of interaction strengths has so far yielded conflicting results.

\section{IMPACTS}

\section{European storm surges \\ Clim. Dynam. http://doi.org/bc6v (2016)}

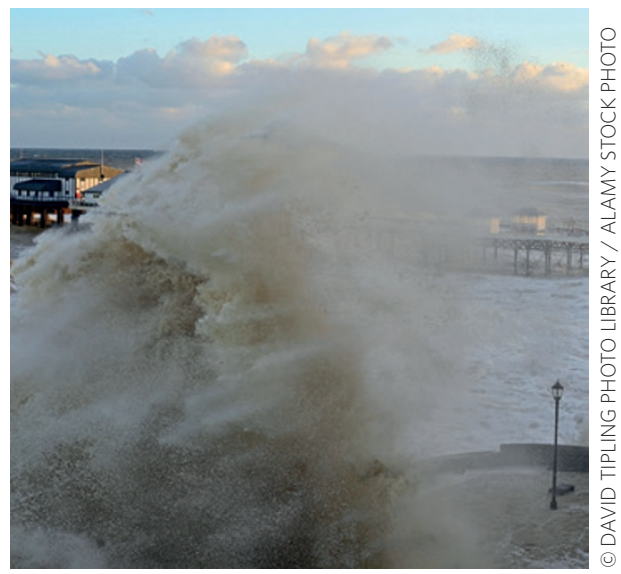

Coastal areas have high population density so changes in water level, both sea-level rise and surges associated with extreme events, are a serious threat. While there is much research on sea-level change, less is known of how storm surges, driven by winds and atmospheric pressure fields associated with storm systems, will change in coming years.

Previous work on extreme storm-surge levels has focused at the local or regional scale, now Michalis Vousdoukas of the European Commission's Joint Research Centre, Ispra, Italy and the University of the Aegean, Lesbos, Greece, and colleagues consider changes across Europe for 2010-2040 and 2070-2100. They use a hydrological model forced with projected wind and pressure fields from 8 CMIP5 models, under moderate- and high-emission scenarios (RCP4.5 and 8.5) and compare with the 1970-2000 baseline period.

The North and Baltic Sea coasts show the largest increases, with the eastern shores experiencing the highest rise. In contrast, southern European coasts have minimal change expected, except under the highemissions scenario. Storm-surge levels are projected to increase around $15 \%$ by 2100 for the entire European coast under the high-emissions scenario, with $14 \%$ of the coastline seeing storm-surge contributions exceeding $30 \%$ of the expected relative sea-level rise. and Bronwyn Wake. 